\title{
Prevalence of Using Hormones and Nutritional Supplements among Gym's Trainee in Saudi Arabia
}

\author{
Yasser Youssef Khojah ${ }^{1 *}$ \\ ${ }^{1}$ King Abdullah Medical Complex in Jeddah, Saudi Arabia \\ *Corresponding Author: Yasser Youssef Khojah, E-mail; Khojah@msn.com
}

\begin{abstract}
Background: worldwide, studies have shown a high prevalence of hormones and nutritional supplements use by athletes and gym members. Many athletes consume unproven, potentially harmful or even banned supplements.
\end{abstract}

Objectives: to assess the prevalence of the use of hormones and nutritional supplements by people who exercise in gyms in Saudi Arabia, and the types of supplements they most commonly use and to obtain a general view of the main reasons for using these enhancements.

Materials and Methods: a cross-sectional study using a self-administered questionnaire was conducted at gyms in Saudi Arabia that were selected randomly from different sectors. The sample size was estimated at 289 , but the actual number of randomly selected participants in the study was 457.

RESULTS: the number of gym members who participated in this study was 457. Approximately $47.9 \%$ of the sample reported an intake of nutritional supplements and $7.9 \%$ reported that they took hormones. Protein powder was consumed by $83.1 \%$ of the participants. Approximately $16.8 \%$ of supplement users had noticed some side effects, and $25.7 \%$ of those who took hormones had stopped taking them because of adverse effects. Only half of the hormone users (54.2\%) reported that they had had medical checkups. The major source of information on supplement and hormone use was non-health professionals, friends being major source (40\%) of information on the use of hormones. The use of nutritional supplements was significantly associated with $\mathrm{BMI}(\mathrm{OR}=1.89, \mathrm{CI}=1.06-3.39)$, duration of daily exercise $(\mathrm{OR}=4.23, \mathrm{CI}=2.06-8.68)$, and following a special diet $(\mathrm{OR}=8.42, \mathrm{CI}=5.37$ 13.2). There was a very strong association between nutritional supplements consumption and hormone use $(P<0.001)$.

CONCLUSION: approximately half of the participants who regularly exercised in gyms took nutritional supplements, and most had received their information from non-health professionals. There was an association between the duration of exercise and the use of hormones and supplements. Fewer than half of hormone users had obtained a health-care provider's advice before taking it. The atmosphere in the gym can play an important role in members' decisions. Educating gym employees and members may have a positive influence on the use of supplements and hormones.

KEYWORDS: Gyms; hormones; Saudi Arabia; nutritional supplements

\section{INTRODUCTION}

The use of hormones and nutritional supplements has become prevalent worldwide. Even more alarming is the fact that multiple studies have shown that a considerable number of people who consume these enhancements sought no medical advice before taking them ${ }^{(1-}$ 5). Different rates of the use of nutritional supplements and hormones have been reported throughout the world. However, limited data are available on the prevalence of their use by regular gym members in Saudi Arabia.
A study was conducted in Riyadh to understand the attitudes of professional footballers on supplements use. The researchers distributed the questionnaires in three famous local sports clubs. Of the105 athletes studied, 93.3\% used different dietary supplements throughout the season. Most of the participants $(88.7 \%)$ had sports drinks, but only $26.5 \%$ took amino acids. Although all individuals were professional footballers, only $45.9 \%$ of them had their information on dietary supplements from a physician ${ }^{(3)}$. 
A study in Beirut, Lebanon, showed that the prevalence of nutritional supplements use was $36.3 \%$ among fitness club participants. The main reason for using these supplements was to improve performance and muscle strength. The supplement most commonly consumed by the participants was protein powder ${ }^{(6)}$.

A study in Tehran, Iran, showed that the prevalence of nutritional supplement use by fitness club members was approximately $66.7 \%$. A small percentage of participants $(0.5 \%)$ took only banned substances. Approximately $11.2 \%$ of participants took both nutritional supplements and banned substances. The authors found that male members were more likely to use prohibited substances than female members ${ }^{(7)}$.

In Al Ain, United Arab Emirates, a study of gym users showed a very high prevalence of the misuse of anabolic steroids (22\%). Most (59\%) users believed that the benefits of using anabolic steroids outweighed the risks. It is possible that some steroid users may have selectively declined to participate in the study for this reason (2). The present study was conducted to assess the prevalence of the use of hormones and nutritional supplements by people who exercise in gyms in Saudi Arabia, and the types of most commonly used supplements, and to ascertain the main reasons for using these enhancements.

\section{Materials and Methods}

The research work was a cross-sectional study, and data were collected using a selfadministered questionnaire. The survey was conducted randomly selected gyms in Saudi Arabia. These gyms were located in the north, south, and east sectors of each city. They also represented the different gym categories, namely, platinum, gold, silver, and bronze, which reflect the subscription fees paid and services provided (towels, massage, barber, etc.,) from the luxurious to the regular. Written permission was obtained from the gym administrators agreeing to participate in the study. The researchers were available to supervise the distribution and collection of the questionnaires and answer any questions posed by participants. Gym employees were not part of this process.

Predesigned questionnaires were used to collect the data. Almost all of the questions were close ended. The participant was able to choose more than one answer if applicable. The questionnaires comprised five main sections: first, socio-demographic data including age, education level, and gym location; second, data on the participant's practice regarding duration and frequency of exercise; third, questions about types of nutritional supplements and hormones available (steroids and growth hormones), whether the respondent took them, and from where they were purchased; fourth, questions on the sources of their knowledge about nutritional supplements and hormones, their reasons for taking them and the average cost; and finally, whether the respondents had benefited from the use of these products. Awareness of the side effects of nutritional supplements and hormones and whether respondents had suffered any adverse effects were also investigated. Possible known side effects of nutritional supplements and hormones were listed, and the participants were asked to give their opinions as follows: $Y e s=$ it is a possible side effect, No = it is not a side effect or I do not know. Responses of "NO" or "I do not know" regarding well known side effects were considered incorrect and indicated a lack of knowledge and awareness.

A pilot study was conducted on fifty participants to test logistics and gather information before the larger study, to improve the quality and efficiency of the survey.

All gym members who were in the gym at the time of the survey were included. Informed consent was obtained from the participants, who were then asked to complete the predesigned questionnaires. We excluded only two incomplete questionnaires.

Descriptive analysis included calculation of means and standard deviations (SDs) for continuous variables and frequencies and percentages for categorical variables. Significant differences in categorical variables such as age, education, and smoking were tested using the Chi square test; $\mathrm{p}<=0.05$ was considered statistically significant. Multiple logistic regression analysis was performed to adjust for confounding and to determine the most significant factors related to supplements use. All statistical analysis was performed using SPSS (Statistical Package for Social Sciences version 20.0, SPSS Inc. Chicago, IL; 2010).

\section{RESULTS}

Table 1 summarizes the basic characteristics of the participants. The sample tended to be 
young; nearly half $(47.7 \%)$ of the participants were between the ages of 18 and 25 years. Most were Saudis $(73.7 \%)$, had a Bachelor's degree (64.1\%); 30.4\% were smokers. The majority $(55.3 \%)$ did not follow a special diet and mean body mass index (BMI) was 25.9 ( $\pm 5 \mathrm{SD})$. Roughly one third of the participants $(35.8 \%)$ had been exercising for more than 1 year. More than half of the sample regularly exercised 3-5 times a week. Nearly three quarters $(72.0 \%)$ exercised for 1-2 $\mathrm{h}$ a day.

Approximately $47.9 \%$ of the sample reported an intake of nutritional supplements; most (83.1\%) took protein powder. Respondents also reported taking vitamins, sports drinks, high carb bars, fat burners, and weight gain supplements. Figure 1 summarizes the percentages of the types of supplements taken by the participants. Regarding the sources of information for the use of the nutritional supplements, just less than half $(49.3 \%)$ of the participants got their information from their coaches, and $28.7 \%$ had it from the Internet. Physicians (23.7\%) and friends $(22.8 \%)$ had less influence on the participants' knowledge. Health food stores (44\%) were the most common source for the purchase of these supplements, followed by friends, coaches, Internet, and private pharmacies.

A high percentage of participants (81.73\%) took the nutritional supplements for bodybuilding. Fewer reported taking them to improve performance, lose weight, or prevent diseases [Figure 2]. An analysis of the participants' characteristics against supplement use showed a statistically significant association between supplements use and smoking, BMI, total duration of attendance at gym, and frequency of exercise and having a special diet $(\mathrm{P}<0.001)$ [Table 2].

Multiple logistic regressions showed that nutritional supplement use was statistically significantly associated with $\mathrm{BMI}(\mathrm{OR}=1.89$, $\mathrm{CI}=1.06-3.39)$, duration of daily exercise (OR $=4.23, \mathrm{CI}=2.06-8.68)$, and following a special diet $(\mathrm{OR}=8.42, \mathrm{CI}=5.37-13.2)$. [Table 3]. Most of the participants $(69.4 \%)$ reported that they had achieved their goals by taking nutritional supplements. Only $16.8 \%$ of the participants had noticed side effects caused by the supplements.

The mean cost of nutritional supplements consumed was 416 Saudi Riyal per month (\$110/month), with a SD of 227 Saudi Riyal. Supplement use was significantly associated with the location of the gym $(\mathrm{P}=0.004)$. More than half $(61.7 \%)$ of the participants who went to gyms on the north side of the city used nutritional supplements [Figure 3].

Only $7.9 \%$ of participants reported using hormones, and most $(75 \%)$ were $<30$ years, but there was no significant association between age and hormone use $(\mathrm{P}=0.195)$. There was a strong association between the total duration of exercise and hormone intake $(\mathrm{P}=0.022)$; approximately $13.4 \%$ of the participants who had been exercising for more than 1 year had a history of hormone use.

Just more than half $(51.4 \%)$ of hormone users took them orally. Only $37.1 \%$ of those who took hormones had received their information from healthcare providers, whereas $31.4 \%$ got their information from friends, $28.5 \%$ from their coaches, and 20\% from the Internet. Only half of respondents $(54.2 \%)$ reported having had full medical checkups before taking the hormones. Most of the participants (65.7\%) justified that they had reached their goals using them. Because of side effects of hormones, $25.7 \%$ of participants had stopped using them. Friends (40\%) were the most common source for obtaining hormones, but some reported purchasing them from the Internet or their coaches.

There was a very strong association between nutritional supplement consumption and hormone use $(\mathrm{P}<0.001)$. Of the total number of those who took hormones, $88.5 \%$ reported taking nutritional supplements also. There was no association between the location of the gym and hormone use. The participants' knowledge of the side effects of the nutritional supplement and hormones is shown in Figures 4 and 5.The participants were mainly aware of the weight gain from both supplement and hormones. About $40 \%$ were aware of frequent urination and gastric upset side effect of the supplement consumption.

Table 1: Socio-demographic characteristics, duration, and frequency of exercise, by use of hormone and nutritional supplements among people exercising at gyms 


\begin{tabular}{|c|c|c|c|}
\hline Characteristics & $\begin{array}{l}\text { Use nutritional } \\
\text { supplement }(n=219) \\
N(\%)\end{array}$ & $\begin{array}{l}\text { Do not use nutritional supplement } \\
(n=238) \\
N(\%)\end{array}$ & $\begin{array}{l}\text { Total } \\
(n=457) \\
N(\%) \\
\end{array}$ \\
\hline \multicolumn{4}{|l|}{ Age group (years) } \\
\hline $18-25$ & $150(48.2)$ & $113(51.8)$ & $218(47.7)$ \\
\hline $26-30$ & $75(53.6)$ & 65 (46.4) & $140(30.6)$ \\
\hline $31-40$ & $30(37.5)$ & $50(62.5)$ & $80(17.5)$ \\
\hline$>40$ & $9(47.4)$ & $10(52.6)$ & $19(4.2)$ \\
\hline \multicolumn{4}{|l|}{ Education } \\
\hline Intermediate & $2(28.6)$ & \begin{tabular}{|l|}
$5(71.4)$ \\
\end{tabular} & $7(1.5)$ \\
\hline High school & $58(46.0)$ & $68(54.0)$ & $126(27.6)$ \\
\hline Bachelor's & $143(48.8)$ & $150(51.2)$ & $293(64.1)$ \\
\hline Master's & $13(52.0)$ & $12(48.0)$ & $25(5.5)$ \\
\hline Above master's & $3(50.0)$ & $3(50.0)$ & $6(1.3)$ \\
\hline \multicolumn{4}{|l|}{ Smoking status } \\
\hline Smoker & $76(55.1)$ & $62(44.9)$ & $138(30.1)$ \\
\hline Nonsmoker & $143(44.8)$ & $176(55.2)$ & $319(69.8)$ \\
\hline \multicolumn{4}{|l|}{ Body mass index (BMI) } \\
\hline Underweight $(<18)$ & $2(28.6)$ & $5(71.4)$ & $7(1.5)$ \\
\hline $\begin{array}{l}\text { Normal weight }(18- \\
24.99)\end{array}$ & $116(54.7)$ & $96(45.3)$ & $212(44.4)$ \\
\hline Overweight (25-29.99) & $87(49.4)$ & $89(50.6)$ & $176(36.7)$ \\
\hline Obese I (30-34.99) & $11(26.2)$ & $31(73.8)$ & $42(8.7)$ \\
\hline Obese II (35-39.99) & $2(16.7)$ & $10(83.3)$ & $12(2.4)$ \\
\hline Obese III (>40) & $1(12.5)$ & $7(87.5)$ & $8(1.5)$ \\
\hline \multicolumn{4}{|l|}{ Total period of exercise } \\
\hline$<1$ month & $11(13.6)$ & $70(86.4)$ & $81(17.8)$ \\
\hline $\begin{array}{l}\text { From } 1 \text { month to } 6 \\
\text { months }\end{array}$ & $60(40.8)$ & $87(59.1)$ & $147(32.0)$ \\
\hline From 7 months to a year & $39(60.0)$ & $26(40.0)$ & $65(14.2)$ \\
\hline More than year & $109(66.5)$ & $55(33.5)$ & $164(35.8)$ \\
\hline \multicolumn{4}{|l|}{$\begin{array}{l}\text { Frequency of exercise } \\
\text { per week }\end{array}$} \\
\hline$<3$ times & $12(17.1)$ & $58(82.9)$ & $70(15.3)$ \\
\hline 3-5 times & $153(53.7)$ & $132(46.3)$ & $285(62.4)$ \\
\hline$>5$ times & $54(52.9)$ & $48(47.1)$ & $102(22.3)$ \\
\hline \multicolumn{4}{|l|}{ Time of daily exercise } \\
\hline$<1 \mathrm{~h}$ & $23(31.5)$ & $50(68.5)$ & $73(16.0)$ \\
\hline $1-2 \mathrm{~h}$ & $170(51.7)$ & $159(48.3)$ & $329(72.0)$ \\
\hline$>2 \mathrm{~h}$ & $26(47.3)$ & $29(52.7)$ & $55(12.0)$ \\
\hline \multicolumn{4}{|l|}{ Following special diet } \\
\hline Yes & $157(77.0)$ & $47(23.0)$ & $204(44.7)$ \\
\hline No & $62(24.5)$ & $191(75.5)$ & $253(55.3)$ \\
\hline
\end{tabular}

Table 2: Association between hormone and nutritional supplement use and various independent variables 
Prevalence of Using Hormones and Nutritional Supplements among Gym's Trainee in Saudi Arabia

\begin{tabular}{|l|l|l|}
\hline Independent variable & Unadjusted OR* (95\% CI**) & Adjusted OR (95\% CI) \\
\hline Age (years) & & \\
\hline$<30$ & $1.556(0.989-2.448)$ & $1.62(0.94-2.81)$ \\
\hline$\geq 30$ & 1.0 (reference) & \\
\hline Education & & $1.88(0.28-12.44)$ \\
\hline$\geq$ High school & $2.328(0.447-12.126)$ & \\
\hline$<$ High school & 1.0 (reference) & $1.38(0.86-2.25)$ \\
\hline Smoking status & & \\
\hline Smoker & $1.509(1.010-2.254)$ & \\
\hline Nonsmoker & 1.0 (reference) & $1.60(0.88-2.91)$ \\
\hline BMI & & \\
\hline Normal or overweight & $2.344(1.423-3.860)$ & $3.86(1.82-8.14)$ \\
\hline Underweight or obese & 1.0 (reference) & \\
\hline Total period of exercise & & $1.52(0.69-3.33)$ \\
\hline$>1$ month & $7.879(4.042-15.357)$ & \\
\hline$\leq 1$ month & 1.0 (reference) & \\
\hline Frequency of exercise & & $1.18(0.59-2.35)$ \\
\hline$>3$ times per week & $5.686(2.962-10.914)$ & \\
\hline$\leq 3$ times per week & 1.0 (reference) & \\
\hline Daily duration of exercise & & \\
\hline$\geq 1 \mathrm{~h}$ & $2.324(1.366-3.954)$ & \\
\hline$<1 \mathrm{~h}$ & 1.0 (reference) & \\
\hline Following special diet & & \\
\hline Yes & $10.335(6.691-15.966)$ & \\
\hline No & 1.0 (reference) & \\
\hline OR O O & & \\
\hline
\end{tabular}

$* \mathrm{OR}=$ Odds ratio, $* * \mathrm{CI}=$ Confidence Interval

Table 3: Multiple logistic regression analysis final models: Correlates of hormone and nutritional supplement use among persons exercising at the gyms

\begin{tabular}{|l|l|l|}
\hline Independent variable & OR* & 95\% CI** for OR \\
\hline Normal weight or overweight & 1.89 & $1.06-3.39$ \\
\hline Daily duration of exercise more than 1 h & 4.23 & $2.06-8.68$ \\
\hline Following special diet & 8.42 & $5.37-13.21$ \\
\hline
\end{tabular}

$* \mathrm{OR}=$ Odds ratio, $* * \mathrm{CI}=$ Confidence Interval

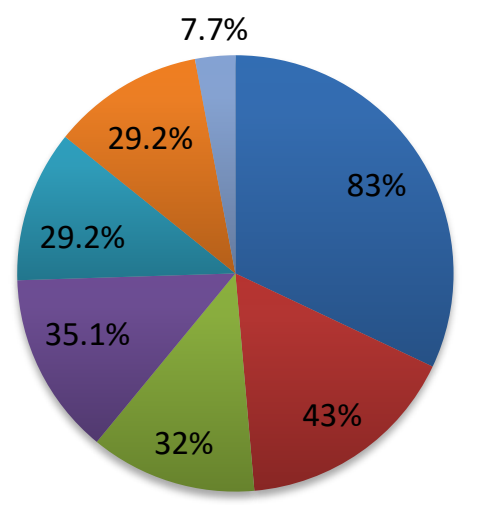

Protein powder

- Vitamins

Sport drinks

- High carb Bars

Fat loss supp.

Weight gain supp.

Others

Figure 1: Types of nutritional supplements used by the study participants 


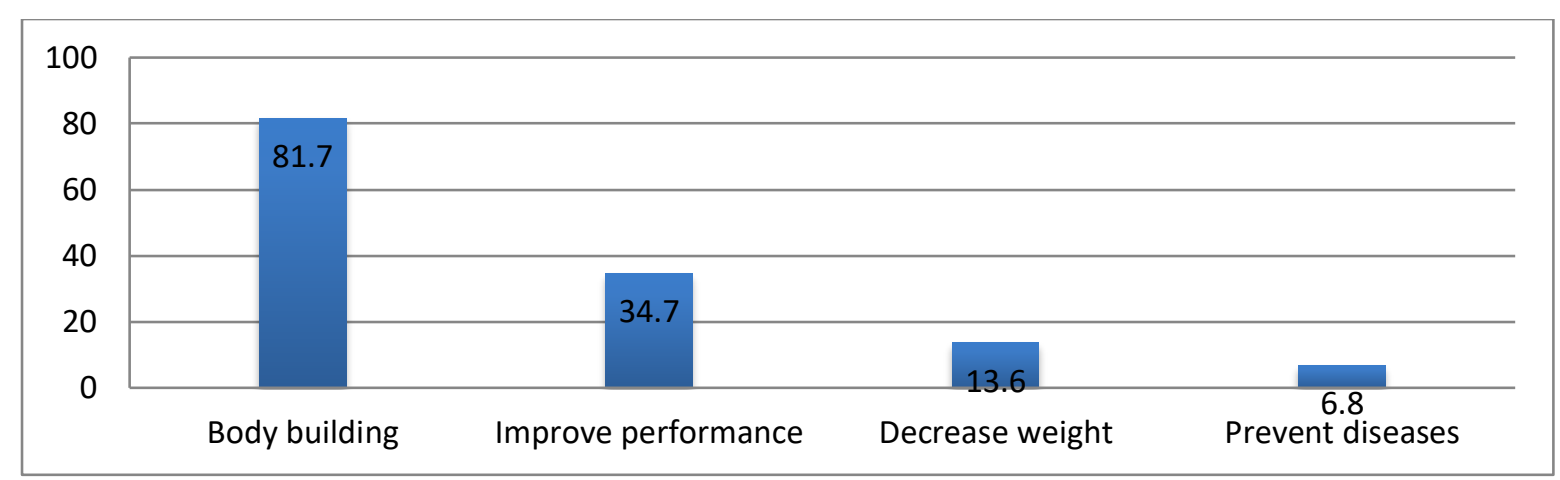

Figure 2: Reasons for nutritional supplement use among study participants

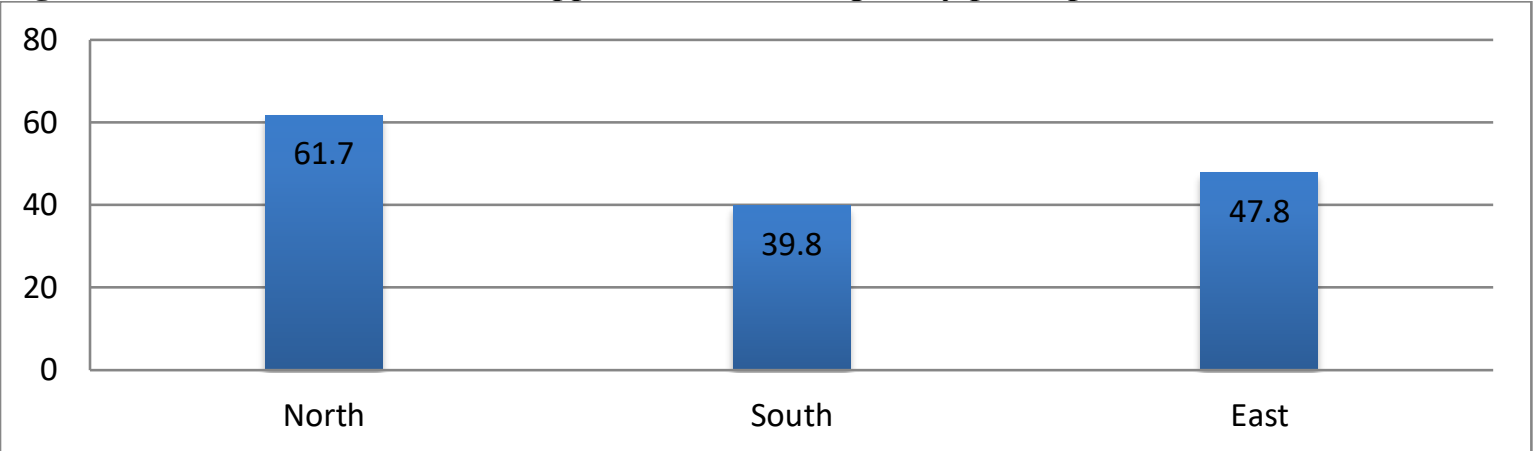

Figure 3: Percentage distribution of nutritional supplement use

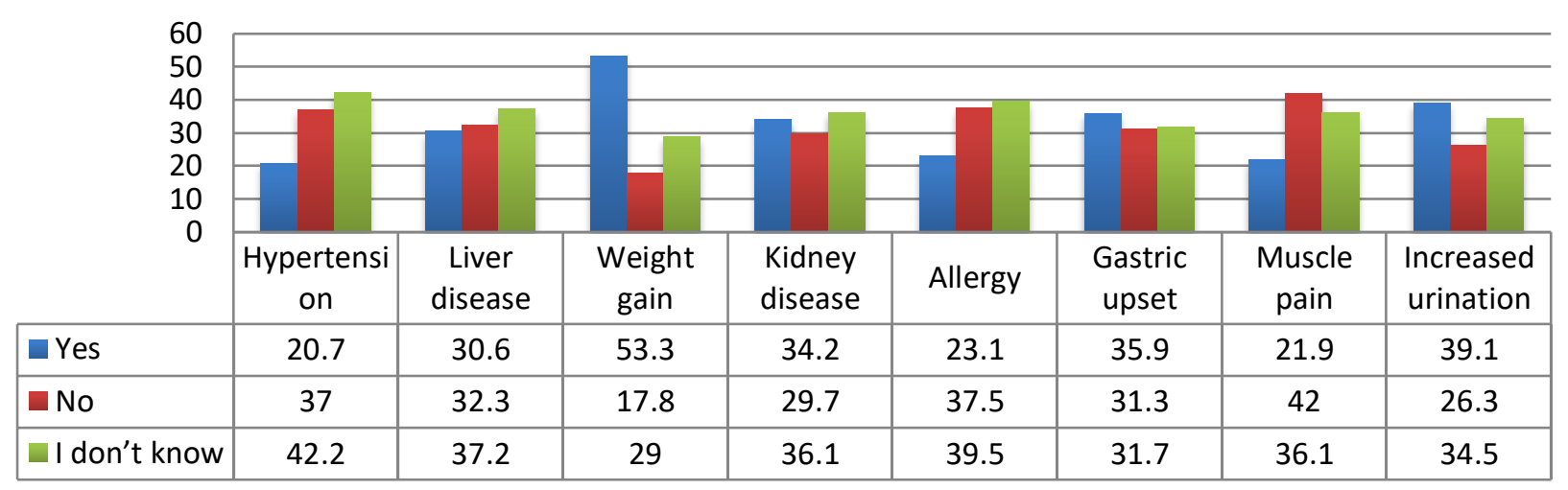

Figure 4: The knowledge of participants regarding various side effects of nutritional supplements use

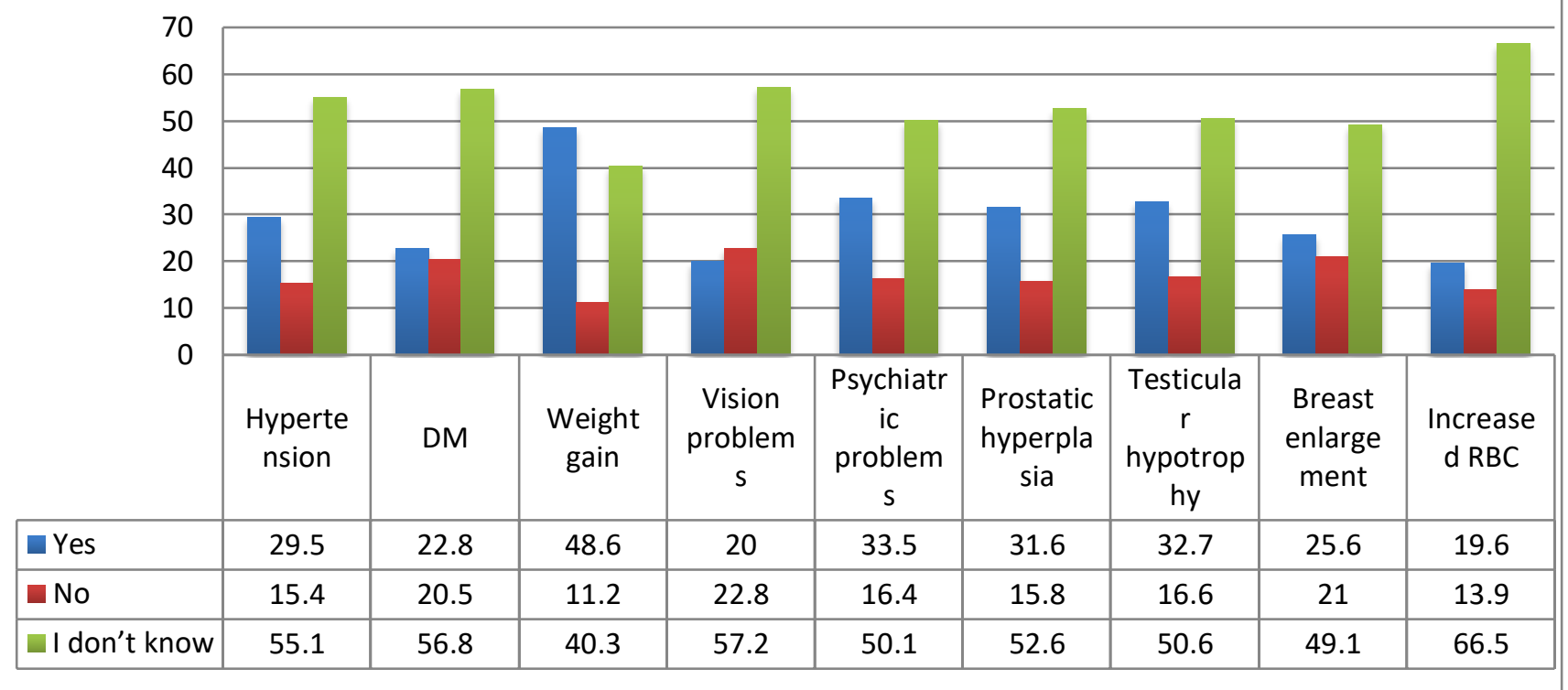

Figure 5: The knowledge of participants regarding various side effects of hormones use 


\section{DISCUSSION}

The present study is the first to illustrate the prevalence of the use of nutritional supplements and hormones by people who exercise in commercial gyms in Saudi Arabia. The study was conducted in gyms that had different activities in order to avoid focusing on persons who were only interested in bodybuilding.

Just less than half of the participants $(47.9 \%)$ reported taking nutritional supplements, compared to a study conducted among professional athletes in Riyadh which reported that $93.3 \%$ of participants were using nutritional supplements ${ }^{(3)}$. This shows a higher rate of nutritional supplements use at all levels among professional athletes and regular gym members. In comparison with other countries, the prevalence of nutritional supplements use in the present study was higher compared to Beirut city $(36.3 \%)^{(6)}$, Brazil $(36.8 \%)^{(8)}$, and Palermo, Italy $(30.1 \%){ }^{(9)}$, but lower than the rate in Tehran (66.7\%) (7). Although supplementation may benefit those with preexisting deficiencies or limited food supply, there is still no conclusive evidence that supplementation enhances health or performance in sports ${ }^{(10)}$.

In both the present study and that conducted in Beirut, the most common type of nutritional supplement used was protein powder, whereas in the study of professional athletes and the study done in Tehran, sports drinks and vitamins were the most common. This difference may be attributable to the different reasons that studied groups for taking nutritional supplements. The present study is comparable to that conducted in Beirut where most of the participants in the two studies used nutritional supplements mainly for bodybuilding. In contrast, most of the participants in the study of professional athletes and the study done Tehran used nutritional supplements because they believed that it made them healthier ${ }^{(3,6,7)}$. Although many studies have shown that individuals who exercise regularly in the gym hardly need nutritional supplements, many participants believe that taking nutritional supplements plays a major role in their improvement ${ }^{(11-13)}$.

In the current study, age had no effect on the tendency toward the use of a particular type of supplement. A large proportion of participants used nutritional supplements without any medical guidance or checkup. The coaches played an important role in encouraging gym members to use nutritional supplements, in that they were the primary source of information for approximately half of the participants. This may indicate that the mood in the gym has a significant influence on the use of nutritional supplements. This indicates the need for coaches to have some medical training or provision of some medical supervision in these gyms to ensure the safety of their members.

We found a significant association between the duration of exercise and supplement use $(\mathrm{P}<$ $0.001)$. There was an association of the use of more supplements with longer periods of exercise. The possible reason for this finding may be increased interest in sports related information or the increased interaction between coaches and athletes. The same finding was also reported by the Beirut study ${ }^{(6)}$. Nearly half of the participants purchased their supplements from either health food stores or pharmacies. The other half purchased their supplements from uncontrolled sources such as friends, the Internet, or coaches.

The analysis of the participants' responses about side effects showed a significant association between supplement use and responses $(\mathrm{P}<0.001)$. With regard to the potential side effects, the supplement users knew the very common problems of weight gain, stomachache, and increased urination perhaps because fellow athletes had shared their experiences. This conclusion supports our hypothesis that the atmosphere in the gym plays a significant role in the acquisition of the knowledge of supplement use. In general, the majority of both groups were not aware of most of the side effects of the nutritional supplement such as high blood pressure, liver disease, kidney disease, allergies, and muscle pain. More than half of the participants (69.4\%) believed that they had reached their goals using nutritional supplements. This figure is nearly double the percentage reported through the Tehran study ${ }^{(7)}$.

This is the first study that estimated the average cost of using nutritional supplements in Saudi Arabia. It was found that the supplements cost on average was 416 Saudi Riyals. (US\$110) per month. There was no significant difference in cost by gym location. Surprisingly, we found a significant association between the location of the gym and supplement use $(P=0.004)$. The gyms in the northern area had higher percentage of users of nutritional supplements, possibly 
because residents in the north have higher incomes than those in other areas. Further research is needed to verify this hypothesis.

Compared with other countries, Saudi Arabia had a lower prevalence of hormone use $(7.9 \%)$ than was found in Al Ain, UAE (22\%) ${ }^{(2)}$, and in Germany $(13.5 \%){ }^{(14)}$. However, the prevalence in this study was higher than that found in Trinidad and Sweden, both of which had a prevalence of $3 \%{ }^{(15,16)}$. The prevalence found in the present study may be an underestimate because dispensing hormones without a prescription is illegal in Saudi Arabia. It is likely that many participants denied using them or refused to participate in the study even after being assured of their anonymity.

In the current study, the most common source for hormones was friends (40\%). This could also have been because of the ban on dispensing hormones without a prescription. There was a strong association between the total duration of exercise and hormone use. The longer the respondent had been exercising, the greater the likelihood of taking hormones $(\mathrm{P}=0.02)$. This finding is most likely the result of the influence of the atmosphere in the gym, which plays a major role in the participants' decision to take supplements or hormones. When gym participants remark the muscles some gym members have been able to develop, they want to achieve the same body building in the shortest possible time. Their peers and sometimes the coach would advise them to take some supplements to speed up the muscle building process. These supplements are usually neither taken on the advice of a health professional nor do the members undergo a medical checkup to evaluate their fitness for gym exercises and the possible nutritional supplements requirement.

The source of information for most of the hormone users is unreliable. It is usually friends, coaches, and/or the Internet. Only $37.1 \%$ reported a healthcare provider as one of their sources. This explains why nearly half of them did not have a medical checkup before they began to take hormones.

Clearly, the study participants lacked valid information, proper medical advice, and checkups. A high percentage of those participated in the current study that took hormones $(25.7 \%)$ may have experienced some side effects, but the adverse effects did not create enough discomfort to make the users stop taking them. Unlike the use of the nutritional supplements, there was no association between gym location and hormone intake. We found a significant association between hormone use and participants' responses $(\mathrm{P}<0.001)$. The majority of both groups were not aware of the side effects of the hormones.

Hormone users had more knowledge about weight gain, psychiatric problems, increased red blood cell count, and prostate hyperplasia as possible side effects. However, they had less knowledge than nonusers about hypertension, diabetes, vision problems, gynecomastia, and testicular hypotrophy $(\mathrm{P}<0.001)$.

The present study has some limitations. It used a self-administered questionnaire survey, which could have introduced self-presentation bias that might have influenced the results. In addition, the study did not give details of the supplements and hormones, such as contents and dosage. These areas are worthy to receive further investigations by researchers in the future.

\section{CONCLUSION}

This study was one of the first to identify the prevalence of the intake of nutritional supplements and hormones by people who exercise at gyms in Saudi Arabia. We found that approximately half of the participants who regularly exercised in gyms used nutritional supplements and that most of them got their information from their coaches. The main reason for taking nutritional supplements was to build muscle. We found an association between the total duration of exercise and the use of supplements.

Of all the participants, $7.9 \%$ reported hormone use. However, less than half of these respondents had taken advice from a healthcare provider before starting taking hormones, and only half reported having a medical checkup. Friends were the most common source of obtaining the hormones. There was a strong association between supplement and hormone use. We found that the atmosphere in the gym played an important role in members' decisions, and we believe that educating coaches and gym employees and raising public awareness could have a positive influence on the use of supplements and hormones. Based on the results of this study, we recommend that health professionals ask questions on the use of nutritional supplements or hormones when they take the medical history of their patients. 
We also recommend that coaches should receive obligatory courses supervised by the Saudi Commission of Health Specialties. This could help in controlling the misuse of nutritional supplement and hormones. On the other hand, educating the public at all levels may help spread the word on the appropriate use of the supplements in the community. There is a need to raise the level of public awareness about the importance of physical activity, eating a balanced diet, and the proper use of nutritional supplements. Health authorities should use all the means available including television, radio, papers, and social media to raise awareness in schools, universities, and other public forums. Health authorities play a pivotal role in the development and review of health requirements in these sports facilities with regard to the integrity of the internal environment, exercise safety, as well as the qualifications and experience of coaches. We also emphasize the important role the Food and Drug Authority to play in monitoring the sale of nutritional supplements and medicines.

\section{REFERENCES}

1. Tian HH, Ong WS, Tan CL (2009): Nutritional supplement use among university athletes in Singapore. Singapore Med J., 50:165-72.

2. Al-Falasi O, Al-Dahmani K, Al-Eisaei $\mathrm{K}$, Al-Ameri S, Al-Maskari F, Nagelkerke $\mathrm{N}$ et al. (2008): Knowledge, attitude and practice of anabolic steroids use among gym users in Al-Ain district, United Arab Emirates. Open Sports Med J., 2:75-81.

3. Aljaloud SO, Ibrahim SA (2013): Use of dietary supplements among professional athletes in Saudi Arabia. J Nutr Metab., 2013:245-349.

4. Froiland K, Koszewski W, Hingst J, Kopecky L (2004): Nutritional supplement use among college athletes and their sources of information. Int $\mathbf{J}$ SportNutr Exerc Metab., 14:104-20.

5. Morrison LJ, Gizis F, Shorter B (2004): Prevalent use of dietary supplements among people who exercise at a commercial gym. Int J Sport Nutr Exerc Metab., 14:481-92.

6. El Khoury D, Antoine-Jonville S
(2012): Intake of nutritional supplements among people exercising in gyms in Beirut city. J Nutr Meta., 703-490.

7. Saeedi P, Mohd Nasir MT, Hazizi AS, Vafa MR, Rahimi Foroushani A (2013): Nutritional supplement use among fitness club participants in Tehran, Iran. Appetite, 60:20-6.

8. Goston JL, Correia MI (2010): Intake of nutritional supplements among people exercising in gyms and influencing factors. Nutrition, 26:604-11.

9. Bianco A, Mammina C, Paoli A, Bellafiore M, Battaglia G, Caramazza G et al. (2011): Protein supplementation in strength and conditioning adepts: Knowledge, dietary behavior and practice in Palermo, Italy. J Int Soc Sports Nutr., $8: 25$.

10. Fogelholm M (2006): Vitamin, mineral and antioxidant needs of athletes. Clinical Sports Nutrition. Roseville: Australia: McGraw-Hill Book Company Australia Pty, Lt.

11. Lukaski HC (2004): Vitamin and mineral status: Effects on physical performance. Nutrition, 20:632-44.

12. Volpe SL (2007): Micronutrient requirements for athletes. Clin Sports Med., 26:119-30.

13. Burke L, Deakin V (1994): Clinical Sports Nutrition. Roseville: Australia: McGraw-Hill Book Company Australia Pty. Ltd.

14. Striegel H, Simon P, Frisch $S$, Roecker K, Dietz K, Dickhuth HH, et al. (2006): Anabolic ergogenic substance users in fitness-sports: A distinct group supported by the health care system. Drug Alcohol Depend, 81:11-9.

15. Maharaj VR, Dookie T, Mohammed S, Ince S, Marsang BL, Rambocas $\mathrm{N}$ et al. (2000): Knowledge, attitudes and practices of anabolic steroid usage among gym users in Trinidad. West Indian Med J., 49:55-8.

16. Nilsson S, Baigi A, Marklund B, Fridlund B (2001): The prevalence of the use of androgenic anabolic steroids by adolescents in a county of Sweden. Eur $\mathbf{J}$ Public Health, 11:195-7. 